\title{
Prevalence of Intimate Partner Violence and Other Lifetime Trauma AMONg Women SEen IN MENTAL HeAlth SeTtings*
}

On average, over half of women seen in a range of mental health settings either currently are or have been abused by an intimate partner although rates vary widely among studies. ${ }^{1,2}$ As noted above, many have also experienced multiple forms of abuse throughout their lives, putting them at greater risk for a range of health and mental health sequelae and affecting their ability to mobilize resources necessary to achieve safety and stability. ${ }^{3-6}$ For example, studies across a variety of mental health settings have found significant rates of lifetime abuse among people living with serious mental illness, with those in inpatient facilities reporting the highest rates (53\% to $83 \%) .7,8,9-15$

Recent studies of adverse childhood experiences also demonstrate the prevalence of lifetime abuse among individuals who have a mental illness. A 2007 study of people diagnosed with schizophrenia found that $86 \%$ had experienced at least one adverse childhood event and $49 \%$ had experienced three or more. ${ }^{16}$ (In this study, adverse events included physical abuse, sexual abuse, parental mental illnesses, loss of a parent, parental separation or divorce, witnessing domestic violence, and foster or kinship care). The number of these events also predicted a range of adverse mental health outcomes (substance abuse, PTSD, length of hospitalization, suicidality, self-rated mental health as well as functional status). While there is no general population study using the same definitions of adverse childhood events, a reasonable comparison can be made with the 1998 ACE study which examined the prevalence of adverse childhood experiences within a large $\mathrm{HMO}$ population. It found that over half of the sample had experienced at least one category of adverse childhood experience and approximately $25 \%$ reported experiencing two or more.17 In this study, the categories of adverse childhood experiences included physical, sexual, or psychological abuse; violence against mother; living with household members who were substance abusers, mentally ill or suicidal, or ever imprisoned.

Although attention to victimization among people receiving public mental health services initially focused on the long-term effects of childhood abuse, rates of adult victimization by acquaintances, strangers, family members and intimate partners appear to be equal or higher. In one study, over $70 \%$ of women admitted for a first psychotic episode had experienced at least one type of abuse and $42 \%$ reported ongoing exposure. ${ }^{18}$ Only a few studies have specifically examined rates of

\footnotetext{
* This is an excerpt from Warshaw, C., Brashler, P., and Gill, J. (2009). Mental health consequences of intimate partner violence. In C. Mitchell and D. Anglin (Eds.), Intimate partner violence: A health based perspective. New York: Oxford University Press.
} 
adult partner, family member or caretaker abuse among individuals with serious mental illnesses. In one inpatient study, $62 \%$ had been abused by a current or former spouse. ${ }^{9}$ Of the $64 \%$ of female inpatients who reported having been physically assaulted as adults in another study, more than half were living with the perpetrator at the time of hospitalization. ${ }^{12}$ In a third study, which looked at hospitalized patients (male and female) who had ongoing relationships with partners or family members, $62.8 \%$ reported a history of physical victimization by a partner, $45.8 \%$ reported physical abuse by a family member, and $29 \%$ reported having experienced domestic abuse within the past year. ${ }^{19}$ Yet, these issues are rarely attended to. Informal focus groups with women who self-identified as consumers of mental health services indicate that the majority had experienced domestic violence and other forms of abuse, but few had been asked about those experiences. The majority of women were also interested in receiving information about domestic violence and about resources they could access in their communities. ${ }^{20}$ Without formal training and policies in place, abusive partners are often included in treatment planning and safety issues go unaddressed.

Until recently, information about specific forms of violence against women, including childhood sexual abuse, sexual assault, and intimate partner violence, was often found in separate literatures. As a result, knowledge about the cumulative effects of lifetime exposure to trauma for adult survivors of intimate partner violence and the experiences of women from diverse communities has been limited. In general, studies examining the mental health impact of intimate partner violence are designed to assess for: 1 ) prevalence of specific psychiatric diagnoses among survivors of intimate partner violence and/or other lifetime trauma, 2) other effects of IPV for which there are validated measurements (e.g., self-esteem, internal vs. external locus of control, functional status), and/or 3) additional factors associated with the frequency or severity of these conditions. Yet, methodological problems and lack of consistency across studies limit the generalizability of much of the currently available research. Measures are not standardized across studies or culturally-normed. And the majority of studies are cross-sectional in design and do not identify the timing of the assessment in relationship to recent crises. Moreover, the majority of studies have been conducted in clinical or shelter settings where rates of symptomatology are likely to be higher.

It is also important to keep in mind the limits of quantitative research for conveying survivors' actual experience. For example, while complex trauma models may ultimately prove to be a more accurate way to understand the multiple effects of chronic longstanding abuse such as IPV, even diagnoses that specifically address traumatic events do not fully capture what living in a climate of fear does to a woman's psychological landscape or what a woman has to do to reconfigure her sense of identity, her belief in herself, her connections to others, and her relationship to a world that has betrayed her. Nor do they convey the unique intersection of strengths, supports, identities and meanings that survivors carry with them as they traverse their lives. 
Despite these limitations, over the past three decades, research documenting the effects of violence across the lifespan indicates that abuse, violence and discrimination play a key role in many of the health and mental health problems experienced by women in the U.S. and throughout the world. ${ }^{17,21,22,23,24-26}$ Researchers have found that exposure to current and/or past abuse is a significant factor in the development and exacerbation of psychiatric disorders, increases the risk for revictimization, and influences the course of recovery from mental illness. ${ }^{16,}$ 27-36

For many abuse survivors, symptoms abate with increased safety and social support, but for others this is not the case. ${ }^{24,37}$ Both random population studies and studies conducted in clinical settings indicate that victimization by an intimate partner places women at significantly higher risk for depression, anxiety, posttraumatic stress disorder, somatization, medical problems, substance abuse and suicide attempts, whether or not they have suffered physical injury and more generally for reporting unmet mental health needs. ${ }^{27,38-42}$ In a meta-analysis of mental health conditions experienced by survivors of intimate partner violence, the weighted mean prevalence across settings was $50 \%$ for depression, $61 \%$ for PTSD and $20.3 \%$ for suicidality. ${ }^{43}$ Rates of depression were highest among women in intimate partner violence shelters $(63.8 \%)$ and court-involved women $(73.7 \%)$, PTSD rates were highest for women in shelters (66.9\%) and drug treatment programs (58.1) and rates of suicide attempts were highest among women seen in psychiatric settings (53.6\%). Somatoform disorders, eating disorders and acute psychotic episodes have also been associated with both adult and childhood abuse.

\section{References}

1. Mowbray CT, Oyserman D, Saunders D, Rueda-Riedle A. Women with severe mental disorders: Issues and service needs. In: Levin BL, Blanch AK, Jennings $A$, eds. Women's Mental Health Services: A Public Health Perspective. Thousand Oaks, CA: Sage; 1998:175-200.

2. Friedman $\mathbf{S H}$, Loue $\mathrm{S}$. Incidence and prevalence of intimate partner violence by and against women with severe mental illness. $J$ Womens Health (Larchmt). May 2007;16(4):471-480.

3. Gladstone GL, Parker GB, Mitchell PB, Malhi GS, Wilhelm K, Austin MP. Implications of childhood trauma for depressed women: An analysis of pathways from childhood sexual abuse to deliberate self-harm and revictimization. Am J Psychiatry. Aug $2004 ; 161(8): 1417-1425$.

4. Mezey G, Bacchus L, Bewley S, White S. Domestic violence, lifetime trauma and psychological health of childbearing women. Bjog. Feb 2005;112(2):197-204.

5. Ramos BM, Carlson BE, McNutt L-A. Lifetime abuse, mental health, and African American women. Journal of Family Violence. Jun 2004;19(3):153-164. 
6. Renner LM, Slack KS. Intimate partner violence and child maltreatment: Understanding intra- and intergenerational connections. Child Abuse Negl. Jun 2006;30(6):599-617.

7. Bryer JB, Nelson BA, Miller JB, Krol PA. Childhood sexual and physical abuse as factors in adult psychiatric illness. Am J Psychiatry. Nov 1987;144(11):1426-1430.

8. Goodman LA, Salyers MP, Mueser KT, et al. Recent victimization in women and men with severe mental illness: prevalence and correlates. J Trauma Stress. Oct $2001 ; 14(4): 615-632$.

9. Carmen EH, Rieker PP, Mills T. Victims of violence and psychiatric illness. Am J Psychiatry. Mar 1984;141(3):378-383.

10. Craine LS, Henson CE, Colliver JA, MacLean DG. Prevalence of a history of sexual abuse among female psychiatric patients in a state hospital system. Hosp Community Psychiatry. Mar 1988;39(3):300-304.

11. Cusack KJ, Grubaugh AL, Knapp RG, Frueh BC. Unrecognized Trauma and PTSD among Public Mental Health Consumers with Chronic and Severe Mental Illness. Community Ment Health J. Oct 2006;42(5):487-500.

12. Jacobson A, Richardson B. Assault experiences of 100 psychiatric inpatients: Evidence of the need for routine inquiry. Am J Psychiatry. Jul 1987;144(7):908-913.

13. Lipschitz DS, Kaplan ML, Sorkenn JB, Faedda GL, Chorney P, Asnis GM. Prevalence and characteristics of physical and sexual abuse among psychiatric outpatients. Psychiatr Serv. Feb 1996;47(2):189-191.

14. Lombardo S, Pohl R. Sexual abuse history of women treated in a psychiatric outpatient clinic. Psychiatr Serv. Apr 1997;48(4):534-536.

15. Rosenberg SD, Lu W, Mueser KT, Jankowski MK, Cournos F. Correlates of adverse childhood events among adults with schizophrenia spectrum disorders. Psychiatr Serv. Feb 2007;58(2):245-253.

16. Felitti VJ, Anda RF, Nordenberg D, et al. Relationship of childhood abuse and household dysfunction to many of the leading causes of death in adults. The Adverse Childhood Experiences (ACE) Study. Am J Prev Med. May 1998;14(4):245-258.

17. Neria Y, Bromet EJ, Sievers S, Lavelle J, Fochtmann LJ. Trauma exposure and posttraumatic stress disorder in psychosis: Findings from a first-admission cohort. $J$ Consult Clin Psychol. Feb 2002;70(1):246-251.

18. Cascardi M, Mueser KT, DeGiralomo J, Murrin M. Physical aggression against psychiatric inpatients by family members and partners. Psychiatr Serv. May 1996;47(5):531-533.

19. Sajdak L. Personal communication. 2005.

20. Crowell NA, Burgess AW. Prevention and intervention. In: Crowell NA, Burgess AW, eds. Understanding Violence Against Women. Washington, DC: National Academy Press; 1996:93-141.

21. Garcia-Moreno C. WHO Multi-country study on women's health and domestic violence against women: Initial results on prevalence, health outcomes, and women's responses. Geneva: World Health Organization; 2005. 
22. Koss MP, Goodman LA, Browne L, Fitzgerald L, Keita G, Russo N, eds. No safe haven: Male violence against women at home, at work, and in the community. Washington, DC: American Psychological Association; 1994.

23. Coker AL, Davis KE, Arias I, et al. Physical and mental health effects of intimate partner violence for men and women. Am J Prev Med. Nov 2002;23(4):260-268.

24. Mueser KT, Rosenberg SD, Goodman LA, Trumbetta SL. Trauma, PTSD, and the course of severe mental illness: An interactive model. Schizophr Res. Jan 1 2002;53(1-2):123-143.

25. Plichta SB, Falik M. Prevalence of violence and its implications for women's health. Womens Health Issues. May-Jun 2001;11(3):244-258.

26. Bebbington PE, Bhugra D, Brugha $T$, et al. Psychosis, victimisation and childhood disadvantage: evidence from the second British National Survey of Psychiatric Morbidity. Br J Psychiatry. Sep 2004;185:220-226.

27. Bonomi AE, Thompson RS, Anderson M, et al. Intimate Partner Violence and Women's Physical, Mental, and Social Functioning. Am J Prev Med. Jun 2006;30(6):458-466.

28. Chapman DP, Whitfield CL, Felitti VJ, Dube SR, Edwards VJ, Anda RF. Adverse childhood experiences and the risk of depressive disorders in adulthood. $J$ Affect Disord. Oct 15 2004;82(2):217-225.

29. Dube SR, Anda RF, Whitfield CL, et al. Long-term consequences of childhood sexual abuse by gender of victim. Am J Prev Med. Jun 2005;28(5):430-438.

30. Edwards VJ, Holden GW, Felitti VJ, Anda RF. Relationship between multiple forms of childhood maltreatment and adult mental health in community respondents: Results from the adverse childhood experiences study. Am J Psychiatry. Aug $2003 ; 160(8): 1453-1460$.

31. Garno JL, Goldberg JF, Ramirez PM, Ritzler BA. Impact of childhood abuse on the clinical course of bipolar disorder. Br J Psychiatry. Feb 2005;186:121-125.

32. Heim C, Nemeroff CB. The role of childhood trauma in the neurobiology of mood and anxiety disorders: preclinical and clinical studies. Biol Psychiatry. Jun 15 2001;49(12):1023-1039.

33. Kessler RC, Chiu WT, Demler O, Merikangas KR, Walters EE. Prevalence, severity, and comorbidity of 12 -month DSM-IV disorders in the National Comorbidity Survey Replication. Arch Gen Psychiatry. Jun 2005;62(6):617-627.

34. Logan TK, Shannon L, Cole J, Walker R. The impact of differential patterns of physical violence and stalking on mental health and help-seeking among women with protective orders. Violence Against Women. Sep 2006;12(9):866-886.

35. McCauley J, Kern DE, Kolodner K, et al. Clinical characteristics of women with a history of childhood abuse: unhealed wounds. Jama. May 7 1997;277(17):13621368.

36. Read J, Perry BD, Moskowitz A, Connolly J. The contribution of early traumatic events to schizophrenia in some patients: A traumagenic neurodevelopmental model. Psychiatry. Winter 2001;64(4):319-345. 
37. Kernic MA, Holt VL, Stoner JA, Wolf ME, Rivara FP. Resolution of depression among victims of intimate partner violence: is cessation of violence enough? Violence Vict. Apr 2003;18(2):115-129.

38. Graffunder CM, Noonan RK, Cox P, Wheaton J. Through a public health lens. Preventing violence against women: an update from the US Centers for Disease Control and Prevention. J Womens Health (Larchmt). Jan-Feb 2004;13(1):5-16.

39. Lipsky S, Caetano R. Impact of intimate partner violence on unmet need for mental health care: results from the NSDUH. Psychiatr Serv. Jun 2007;58(6):822-829.

40. Kaslow NJ, Thompson MP, Okun A, et al. Risk and protective factors for suicidal behavior in abused African American women. J Consult Clin Psychol. Apr $2002 ; 70(2): 311-319$.

41. Kovac SH, Klapow JC, Kroenke K, Spitzer RL, Williams JB. Differing symptoms of abused versus nonabused women in obstetric-gynecology settings. Am J Obstet Gynecol. Mar 2003;188(3):707-713.

42. McCauley J, Kern DE, Kolodner K, Derogatis LR, Bass EB. Relation of low-severity violence to women's health. J Gen Intern Med. Oct 1998;13(10):687-691.

43. Golding JM. Unpublished manuscript. Chicago: Domestic Violence and Mental Health Policy Initiative; 2000. 